\title{
Nasopharyngeal colonisation dynamics of bacterial pathogens in patients with fever in rural Burkina Faso: an observational study
}

Liesbeth Martens ${ }^{1,2,3^{*}}$, Bérenger Kaboré ${ }^{3,4,5}$, Annelies Post ${ }^{3,4}$, Christa E. van der Gaast-de Jongh ${ }^{1,3}$, Jeroen D. Langereis ${ }^{1,3}$, Halidou Tinto ${ }^{5}$, Jan Jacobs ${ }^{6,7}$, André J. van der Ven ${ }^{3,4}$, Quirijn de Mast ${ }^{3,4}$ and Marien I. de Jonge $\mathrm{e}^{1,3}$

\begin{abstract}
Background: Nasopharyngeal colonisation with clinically relevant bacterial pathogens is a risk factor for severe infections, such as pneumonia and bacteraemia. In this study, we investigated the determinants of nasopharyngeal carriage in febrile patients in rural Burkina Faso.

Methods: From March 2016 to June 2017, we recruited 924 paediatric and adult patients presenting with fever, hypothermia or suspicion of severe infection to the Centre Medical avec Antenne Chirurgicale Saint Camille de Nanoro, Burkina Faso. We recorded a broad range of clinical data, collected nasopharyngeal swabs and tested them for the presence of Streptococcus pneumoniae, Haemophilus influenzae, Moraxella catarrhalis, Staphylococcus aureus and Klebsiella pneumoniae by quantitative polymerase chain reaction. Using logistic regression, we investigated the determinants of carriage and aimed to find correlations with clinical outcome.

Results: Nasopharyngeal colonisation with S. pneumoniae, H. influenzae and M. catarrhalis was highly prevalent and strongly dependent on age and season. Females were less likely to be colonised with S. pneumoniae (OR 0.71, $\mathrm{p}=0.022,95 \% \mathrm{Cl} 0.53-0.95$ ) and $\mathrm{M}$. catarrhalis (OR 0.73, $\mathrm{p}=0.044,95 \% \mathrm{Cl} 0.54-0.99)$ than males. Colonisation rates were highest in the age groups $<1$ year and $1-2$ years of age and declined with increasing age. Colonisation also declined towards the end of the rainy season and rose again during the beginning of the dry season. K. pneumoniae prevalence was low and not significantly correlated with age or season. For S. pneumoniae and H. influenzae, we found a positive association between nasopharyngeal carriage and clinical pneumonia [OR 1.75, $\mathrm{p}=0.008,95 \% \mathrm{Cl} 1.16-2.63$ (S. pneumoniae) and OR 1.90, $\mathrm{p}=0.004,95 \% \mathrm{Cl} 1.23-2.92$ (H. influenzae)]. S. aureus carriage was correlated with mortality (OR 4.01, $\mathrm{p}<0.001,95 \% \mathrm{Cl} 2.06-7.83)$, independent of bacteraemia caused by this bacterium.
\end{abstract}

Conclusions: Age, sex and season are important determinants of nasopharyngeal colonisation with S. pneumoniae, H. influenzae and M. catarrhalis in patients with fever in Burkina Faso. S. pneumoniae and H. influenzae carriage is associated with clinical pneumonia and $\mathrm{S}$. aureus carriage is associated with mortality in patients with fever. These findings may help to understand the dynamics of colonisation and the associated transmission of these pathogens.

\footnotetext{
*Correspondence: Liesbeth.martens@radboudumc.nl

${ }^{1}$ Department of Laboratory Medicine, Laboratory of Medical

Immunology, Radboud university medical center, Nijmegen, the

Netherlands

Full list of author information is available at the end of the article
}

(C) The Author(s) 2021. Open Access This article is licensed under a Creative Commons Attribution 4.0 International License, which permits use, sharing, adaptation, distribution and reproduction in any medium or format, as long as you give appropriate credit to the original author(s) and the source, provide a link to the Creative Commons licence, and indicate if changes were made. The images or other third party material in this article are included in the article's Creative Commons licence, unless indicated otherwise in a credit line to the material. If material is not included in the article's Creative Commons licence and your intended use is not permitted by statutory regulation or exceeds the permitted use, you will need to obtain permission directly from the copyright holder. To view a copy of this licence, visit http://creativecommons.org/licenses/by/4.0/. The Creative Commons Public Domain Dedication waiver (http://creativeco mmons.org/publicdomain/zero/1.0/) applies to the data made available in this article, unless otherwise stated in a credit line to the data. 
Furthermore, understanding the determinants of nasopharyngeal colonisation and the association with disease could potentially improve the diagnosis of febrile patients.

Keywords: Nasopharyngeal carriage, Streptococcus pneumoniae, Haemophilus influenzae, Moraxella catarrhalis, Staphylococcus aureus, Klebsiella pneumoniae, Burkina Faso

\section{Background}

The human nasopharynx is the main reservoir for wellknown respiratory pathogens such as Streptococcus pneumoniae, Haemophilus influenzae and Moraxella catarrhalis [1-3]. It is also a secondary reservoir for Staphylococcus aureus, which preferentially colonises the nares but can be found throughout the respiratory tract as well as the gastrointestinal tract and the skin [4]. Klebsiella pneumoniae, a microorganism that primarily colonises the gastrointestinal tract, is occasionally found in the nasopharynx and is an important cause of community acquired pneumonia (CAP) in low-income countries [5-7].

Nasopharyngeal carriage of these bacteria is usually harmless and asymptomatic. However, under specific conditions they can enter the lungs, the bloodstream or even the central nervous system and cause systemic disease [1-5]. Additionally, the human nasopharynx acts as a hub from where these pathogens are transmitted to other people, leading to spread within the population.

Information on the epidemiology and dynamics of nasopharyngeal carriage of S. pneumoniae, H. influenzae, M. catarrhalis, S. aureus and K. pneumoniae is limited. The notable exception to this is the effect of pneumococcal vaccination on nasopharyngeal carriage of $S$. pneumoniae in children in West Africa [8-11]. Another known fact is that there are major regional differences in the rates of carriage [12]. A relatively high nasopharyngeal prevalence of $K$. pneumoniae has been reported in low-income countries, which could explain why this bacterium is a much more common cause of CAP in these countries, as compared to high-income countries [6, $7,12]$. Some research has also been published on the influence of season, age, sex and rurality, mainly on $S$. pneumoniae [8, 9, 13-17]. Data on nasopharyngeal colonisation with $H$. influenzae, $M$. catarrhalis, $S$. aureus and K. pneumoniae in West Africa are sparse, especially for adults and with regard for seasonal influences $[8,10,16$, 18-20].

Considering these gaps in knowledge, we aimed to perform a cross-sectional study with an adequate number of inclusions throughout the year so as to create a better understanding of the epidemiology of nasopharyngeal carriage of these pathogens. We believe these data could provide insight into the epidemiological determinants of the infections caused by the studied pathogens. This knowledge may also be a starting point for determining which interventions could lead to a lower incidence of these infections. We hypothesized that season was a major determinant of carriage for nasopharyngeal carriage of S. pneumoniae, $H$. influenzae, $M$. catarrhalis, $S$. aureus and $K$. pneumoniae and aimed to document the seasonal dynamics of carriage of these bacteria. We further hypothesized that there would be a correlation with $\mathrm{HIV}$, malaria and/or tuberculosis and that carriage of one pathogen could influence carriage of the others. Lastly, we aimed to show the clinical relevance of our findings by demonstrating a correlation between carriage and clinical disease and/or outcome.

\section{Methods}

\section{Study area and design}

This study was designed as a side project to the PALUBAC study, which was set up to test and optimise an algorithm to distinguish malaria from bacterial infections in acutely ill febrile patients. Inclusion and exclusion criteria of the PALUBAC study and a complete report on which data were collected have been published previously [21-23]. Briefly, participants were enrolled between March 2016 and June 2017 at the Centre Médical avec Antenne Chirurgicale (CMA) Saint Camille de Nanoro, Burkina Faso. Nanoro is located in the central-western part of the country. It has a rainy season from June to October, with an average rainfall of $450-700 \mathrm{~mm}$ per year, and a dry season from November to May [24]. The Nanoro department is a rural area with an average population density of $139 / \mathrm{km}^{2}$. The majority $(90.13 \%)$ of the population lives in rural conditions. The principal activity of the inhabitants is agriculture, mainly subsistence farming. $50.57 \%$ of inhabitants are children under 15 years of age [25]. The national immunisation program has included the conjugate $H$. influenzae type B vaccine since 2006 and the 13-valent conjugate S. pneumoniae vaccine since 2013. Children under 5 years of age receive seasonal malaria chemoprophylaxis from July to October. Participants were eligible for inclusion if they had a fever (temperature $\geq 38.0{ }^{\circ} \mathrm{C}$ ), hypothermia (temperature $\leq 35.5^{\circ} \mathrm{C}$ ), a reported history of fever or hypothermia up to $48 \mathrm{~h}$ prior to presentation at the health facility or a suspicion of severe infection. Patients under 3 months of age and patients with fever or hypothermia lasting longer than 7 days were excluded. From March until November 2016, 
only hospitalised patients were enrolled. Thereafter, until the end of the study in June 2017, non-hospitalised patients were also enrolled because of insufficient study recruitment [23].

Basic demographic and clinical data were recorded on a standardized case report form by study nurses. Upon inclusion, a blood sample was taken, as well as a nasopharyngeal swab in UTM medium. The blood sample was used for malaria diagnostics (rapid diagnostic tests, thin and thick film microscopy), blood culture and basic hemocytometry. Cultures of urine, stool, pus or cerebrospinal fluid and imaging diagnostics (chest X-ray or abdominal echography) were performed only when indicated, as was serology for specific infectious diseases (e.g. HIV). Residual blood and the nasopharyngeal swabs were stored at $-20{ }^{\circ} \mathrm{C}$ and shipped to the Radboud university medical center in Nijmegen, the Netherlands. There, all blood samples were tested for malaria using quantitative polymerase chain reaction (qPCR). qPCR for Salmonella spp., S. pneumoniae, H. influenzae and S. aureus was performed on blood samples of patients with negative blood cultures. qPCR methods for the detection of bacterial pathogens in blood samples were described in a previous publication [23]. The detection limit was 75 copies of DNA per ml of blood.

For the purpose of data analysis, 'bacteraemia' was defined as the presence of a pathogenic bacterium either in blood culture or in blood qPCR. Upon discharge, a final diagnosis made by a local physician was recorded on the case report form. For children below 5 years of age, pneumonia was defined according to the WHO criteria [26]. For older children and adults, pneumonia was defined as patients having fever and one or more signs of dyspnoea (rapid breathing, nasal flaring, chest indrawing, saturation below 95\%, subjective feeling of dyspnoea), combined with either an X-ray showing pulmonary infiltrate or chest auscultation suspect for pneumonia. The criteria for a diagnosis of tuberculosis were cough lasting $\geq 14$ days and weight loss, in combination with (1) a positive Mycobacterium tuberculosis PCR (GeneXpert ${ }^{\circledR}$ MTB/RIF) on sputum, (2) acid-fast bacteria in ZiehlNeelsen stain on sputum or (3) typical caseating granulomas on X-ray.

\section{qPCR analysis on nasopharyngeal swab samples}

qPCR for S. pneumoniae, $H$. influenzae, M. catarrhalis, $S$. aureus and K. pneumoniae was performed on all nasopharyngeal swabs. Stored swab samples were thawed on ice and vortexed. From each sample, $200 \mu \mathrm{l}$ was aliquoted into a 96-wells plate. The plate was incubated for $15 \mathrm{~min}$ at $93{ }^{\circ} \mathrm{C}$ to lyse the bacteria [27]. The qPCR was performed in five monoplex reactions, using the Biorad CFX96 Touch Real-Time PCR Detection System. All reactions were performed in a $10 \mu \mathrm{l}$ final volume containing $1 \mu \mathrm{l}$ bacterial lysate, $5 \mu \mathrm{l}$ SsoAdvanced ${ }^{\mathrm{TM}}$ Universal Probes Supermix (Bio-Rad), $400 \mathrm{nM}$ of each primer and $200 \mathrm{nM}$ probe. For details on primers and probes, see Additional file 1: Sheet 1. Every 96-wells plate contained, in duplicate, a no template control and a seven step tenfold serial dilution of a positive control, starting at approximately $10 \mathrm{ng} / \mu \mathrm{l}$. The qPCR program consisted of $3 \mathrm{~min}$ of incubation at $95{ }^{\circ} \mathrm{C}$ followed by 50 cycles of $10 \mathrm{~s}$ at $95{ }^{\circ} \mathrm{C}$ and $20 \mathrm{~s}$ at $60^{\circ} \mathrm{C}$ for all targets except for K. pneumoniae, for which the cycles were $10 \mathrm{~s}$ at $95{ }^{\circ} \mathrm{C}$ and $20 \mathrm{~s}$ at $65^{\circ} \mathrm{C}$. Fluorescence was measured after each cycle. In order to accurately compare results within targets, the baseline threshold was adjusted so that the log 3 dilutions of the positive control had the same $\mathrm{Cq}$ value per target for all 12 plates. Cq cutoff was determined per target using data on negative controls and samples that were tested in duplicate. The detection limit of the qPCR was calculated to be below ten copies of DNA per $\mu \mathrm{l}$ UTM medium for all targets. All qPCR results can be viewed online (Additional file 2).

\section{Statistical analyses}

Data were analysed using SPSS Statistics 25.0.0.1 (IBM, Armonk, New York, USA). Carriage prevalences were estimated from logistic regression models adjusted for by sex (male), age (5.0 years) and/or month of inclusion (January). Odds ratios and p-values were calculated after adjustment for age, sex and month of inclusion using logistic regression. p Values below 0.05 were considered statistically significant. The SPSS output file can be viewed online (Additional file 3).

\section{Ethical approval}

The study protocol was approved by the national ethics committee of Burkina Faso, the institutional review board of IRSS, the ethical committee of the University of Antwerp and the internal review board of the Institute of Tropical Medicine Antwerp, Belgium. Written informed consent was obtained from all participants or their parents/legal guardians with additional assent from those aged 7 to 15 years.

\section{Results}

\section{Study population and general colonisation rates}

A total of 984 patients met the inclusion criteria for the PALUBAC study, 54 of whom were not included: 27 patients refused participation, 15 patients were referred to another hospital before they could be included, 4 patients died before they could be included and 8 were not included for other reasons. A total of 930 patients were enrolled, 6 of whom were excluded from this 
analysis because they did not provide a nasopharyngeal swab, resulting in a final number of 924 patients.

More patients were included in the dry season, as compared to the rainy season ( 83 vs 68 patients per month) and more males than females were included (533 males vs 391 females) (Table 1 and Additional file 1: Sheet 2). The age of included patients ranged from 3 months to 90 years, with a median of 5.0 years. Out of 565 children below the age of 12 years, $62(11.0 \%)$ were classified as

Table 1 General characteristics of the study population

\begin{tabular}{llr}
\hline Characteristic & $\mathbf{n}$ & $\%$ \\
\hline Sex & 391 & 42.3 \\
Female & 533 & 57.7 \\
Male & & \\
Age group & 152 & 16.5 \\
$<1$ years & 213 & 23.1 \\
1-2 years & 115 & 12.4 \\
3-5 years & 85 & 9.2 \\
6-11 years & 359 & 38.9 \\
12+ years & & \\
Malnutrition & \\
$<1$ years & 24 & 15.8 \\
1-2 years & 32 & 15.0 \\
3-5 years & 6 & 5.2 \\
6-11 years & 0 & 0.0 \\
Malaria status & & \\
Microscopy positive & 247 & 10.4 \\
Microscopy negative, PCR positive & 96 & \\
\hline
\end{tabular}

${ }^{\S}$ Malnutrition was defined as a WHO Anthro weight-for-height z-score <2. Data on malnutrition were only recorded for patients below 12 years of age malnourished, which was defined as a WHO Anthro weight-for-height $\mathrm{z}$-score $<2$.

After admittance, 713 patients $(77.2 \%)$ were eventually discharged because they had improved clinically, 128 (13.9\%) were referred to another hospital, 50 patients (5.4\%) died and 33 (3.6\%) left against medical advice.

Overall, the unadjusted prevalence of carriage in our study group was 0.44 (S. pneumoniae), 0.30 (H. influenzae), 0.47 (M. catarrhalis), 0.17 (S. aureus) and 0.04 (K. pneumoniae). K. pneumoniae carriage was consistently below $10 \%$ in all age groups and throughout the year (Figs. 1 and 2). After adjustment for age and month of inclusion, females were overall less likely to be colonised with $S$. pneumoniae (OR 0.71, $\mathrm{p}=0.022,95 \%$ CI 0.53-0.95) and $M$. catarrhalis (OR 0.73, $\mathrm{p}=0.044$, 95\% CI 0.54-0.99) than males.

The prevalence of colonisation with S. pneumoniae, $H$. influenzae and $M$. catarrhalis was highest in the age groups $<1$ year and 1-2 years of age and then decreased sharply with increasing age. S. aureus colonisation showed a peak in the 6-11 years age group but was otherwise constant. K. pneumoniae carriage did appear to be higher in the younger age groups, although no statistically significant linear correlation was found (Fig. 1).

The colonisation rates for S. pneumoniae, $H$. influen$z a e$ and $M$. catarrhalis showed a marked seasonal association, with rates 2.0-2.9 times higher in January (dry season) as compared to September (rainy season). $S$. aureus colonisation over the year was more erratic and did not follow a clear seasonal pattern. K. pneumoniae colonisation rates did not significantly vary over the months (Fig. 2).

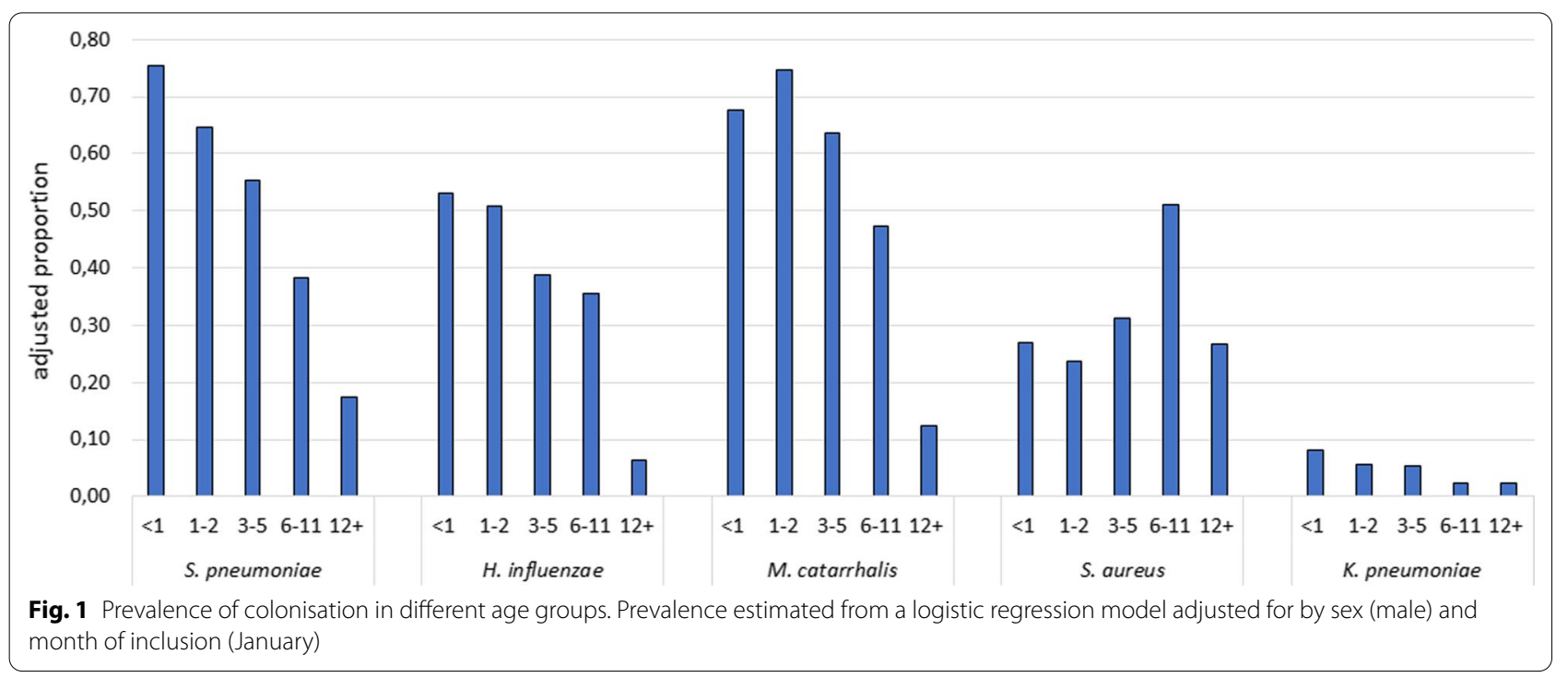




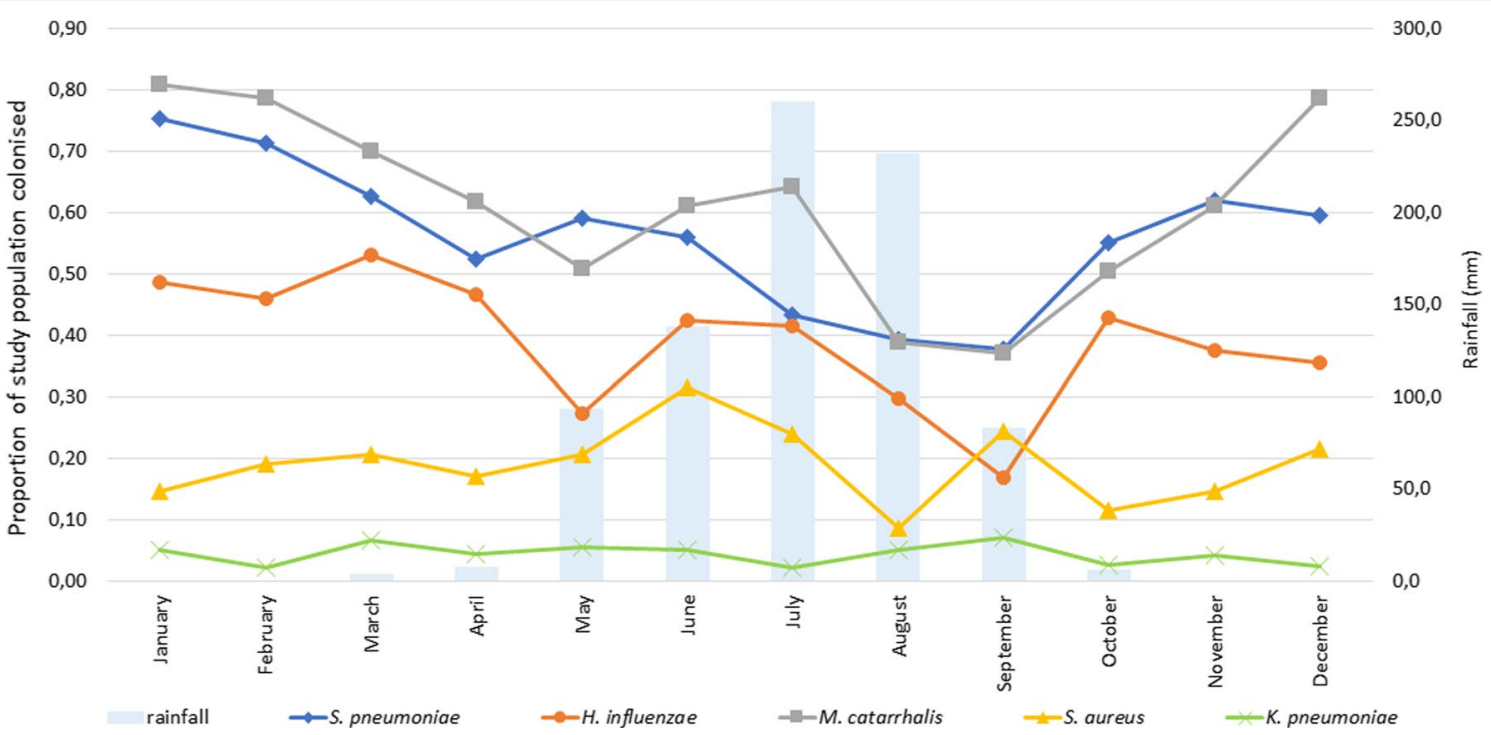

Fig. 2 Proportion of study population colonized and rainfall during the study period by month of year. Proportions estimated from a logistic regression model adjusted for by sex (male) and age (5.0 years)

\section{Correlation between colonisation and clinical disease}

Out of 924 patients who provided a nasopharyngeal swab, 155 were diagnosed with pneumonia. A total of 584 patients were diagnosed with one or more conditions other than pneumonia and the remaining 186 patients were discharged from the hospital with a diagnosis that neither in- or excluded pneumonia (e.g. 'septicaemia' without specification of the primary focus). We found higher odds for pneumonia in carriers of $S$. pneumoniae (OR 1.75, $\mathrm{p}=0.008,95 \% \mathrm{CI} 1.16-2.63)$ and $H$. influenzae (OR1.90, $\mathrm{p}=0.004,95 \%$ CI 1.23-2.92), but not $M$. catarrhalis (OR 1.13, $\mathrm{p}=0.59,95 \%$ CI 0.73-1.73) (Fig. 3a).
'Bacteraemia' was defined as the presence of a pathogenic bacterium either in blood culture or in blood qPCR. 88 patients had positive blood cultures, a further 40 patients had positive blood qPCR. In total, 128 patients (13.9\%) were bacteraemic: 27 with S. pneumoniae, 20 with $H$. influenzae, 11 with $S$. aureus, 1 with $K$. pneumoniae and 72 with other bacteria (Additional file 1: Sheet 3). Three patients were bacteraemic with two different bacteria.

Colonisation with S. pneumoniae gave higher odds for S. pneumoniae bacteraemia (OR 9.63, p $<0.001,95 \%$ CI3.28-28.24). Nasopharyngeal colonisation, however, a.

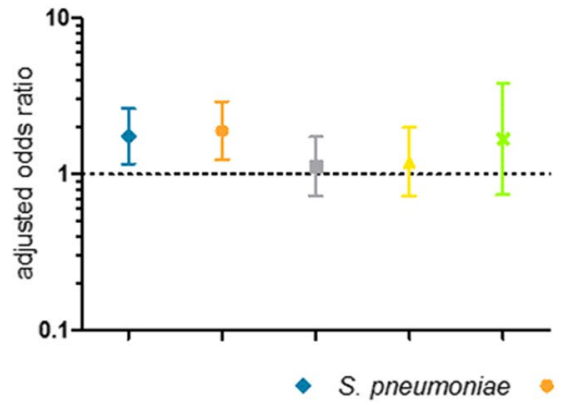

b.

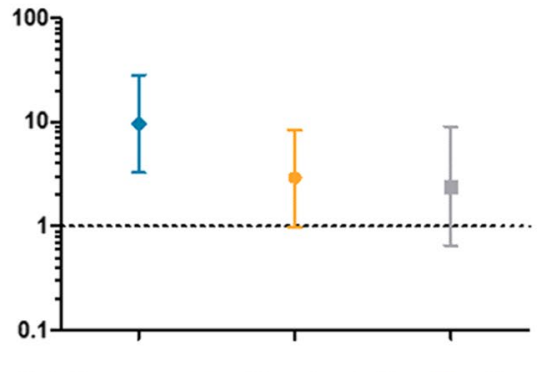

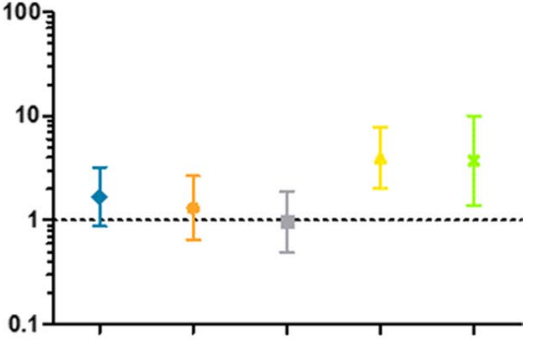

K. pneumoniae

Fig. 3 Adjusted odds ratio with 95\% confidence interval for a discharge diagnosis of pneumonia in S. pneumoniae, H. influenzae, M. catarrhalis, S. aureus and K. pneumoniae carriers versus noncarriers, $\mathbf{b}$ bacteraemia with S. pneumoniae, H. influenzae and S. aureus in carriers of the same bacterium versus noncarriers, c mortality in S. pneumoniae, H. influenzae, M. catarrhalis, S. aureus and K. pneumoniae carriers versus noncarriers. Figures show the correlation between determinants (S. pneumoniae, H. influenzae, M. catarrhalis, S. aureus and K. pneumoniae carriage) and outcome variables [discharge diagnosis of pneumonia (a), bacteraemia (b) and mortality (c)], after adjustment for age, sex and month of inclusion, calculated using separate logistic regression models 
was not a prerequisite for bacteraemia: nasopharyngeal swabs for 5 out of 27 (18.5\%) patients with pneumococcal bacteraemia tested negative for S. pneumoniae. In $H$. influenzae and S. aureus, the correlation between colonisation and bacteraemia was not statistically significant (Fig. 3b).

Remarkably, nasopharyngeal carriage of S. aureus was associated with bacteraemia and mortality, independent of disease caused by $S$. aureus itself. S. aureus carriers had similarly high odds ratios for bacteraemia with S. aureus $(\mathrm{n}=11)(\mathrm{OR} 2.44, \mathrm{p}=0.18,95 \%$ CI 0.66-9.10, adjusted for age, sex and month of entry using a logistic regression model) and bacteraemia with other bacteria $(\mathrm{n}=117)$ (OR 2.27, $\mathrm{p}=0.001,95 \%$ CI 1.42-3.63, adjusted for age, sex and month of entry using a logistic regression model) as compared to $S$. aureus noncarriers. Additionally, S. aureus colonisation was associated with lethal outcome (OR 4.01, p < 0.001, 95\% CI 2.06-7.83) (Fig. 3c), even after adjustment for bacteraemia (OR 3.54, $\mathrm{p}<0.001$, 95\% CI1.79-7.02). We did not find this association in $S$. pneumoniae, $H$. influenzae or S. aureus. K. pneumoniae colonisation did appear to be correlated with mortality (OR 3.73, $\mathrm{p}=0.009,95 \% \mathrm{CI} 1.38-10.07$, adjusted for age, sex and month of entry using a logistic regression model), but with a very wide confidence interval due to low numbers.

\section{Influence of HIV, tuberculosis and malaria}

HIV positive patients $(\mathrm{n}=33)$ had somewhat higher odds for colonisation with S. pneumoniae, $H$. influenzae, $M$. catarrhalis and S. aureus, although none of these correlations reached statistical significance (Fig. 4a). Patients diagnosed with tuberculosis $(\mathrm{n}=20)$, on the other hand, were less likely to be colonised with $S$. pneumoniae and M. catarrhalis (Fig. 4b). No patients with tuberculosis tested positive for K. pneumoniae. The impact of malaria $(\mathrm{n}=343)$ on nasopharyngeal colonisation was less pronounced (Fig. 4c), although a positive correlation with $M$. catarrhalis colonisation did reach statistical significance (OR 1.58, $\mathrm{p}=0.01,95 \%$ CI 1.12-2.22).

\section{Co-occurrence of carriage}

643 patients $(69.6 \%)$ tested positive for colonisation with at least one of the included bacteria. 416 of them $(45.0 \%$ of the total) were colonised with multiple bacteria. The influence of nasopharyngeal colonisation with any of the five tested bacteria on colonisation with any of the four others was highly age-specific. In general, associations between carriage with $S$. pneumoniae, $H$. influen$z a e$ and $M$. catarrhalis were positive for children $<1$ year and indifferent or negative in higher age groups, like for example the association between carriage of $M$. catarrhalis and S. pneumoniae (Fig. 5a and Additional file 1: Sheet 4). The odds for $S$. aureus colonisation generally rose for patients aged 12 years and older when colonised with S. pneumoniae, $H$. influenzae or M. catarrhalis, but in the younger age groups the opposite effect was visible (Fig. 5b and Additional file 1: Sheet 4).

\section{Discussion}

In this study, we report a high prevalence of nasopharyngeal colonisation with S. pneumoniae, $H$. influenzae, $M$. catarrhalis and $S$. aureus in children and adults presenting to the hospital with an acute febrile illness in rural Burkina Faso. The prevalence of colonisation with $S$. pneumoniae, $H$. influenzae and $M$. catarrhalis was dependent on age and season. K. pneumoniae prevalence was low and not significantly correlated with age, season or carriage of other bacteria. The results suggest that nasopharyngeal carriage of $S$. pneumoniae, $H$. influenzae a.

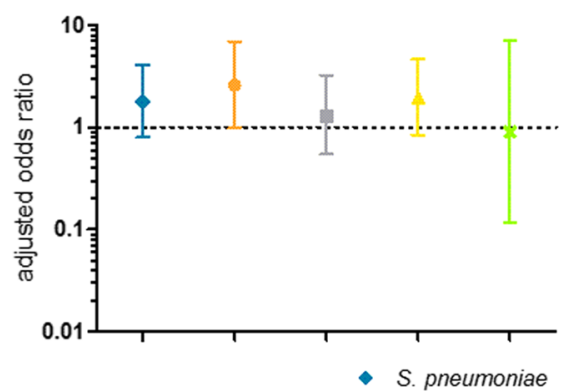

b.

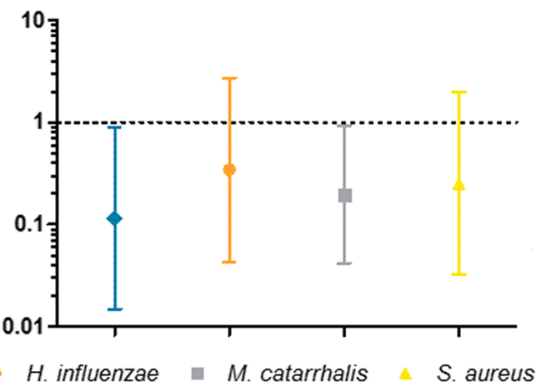

c.

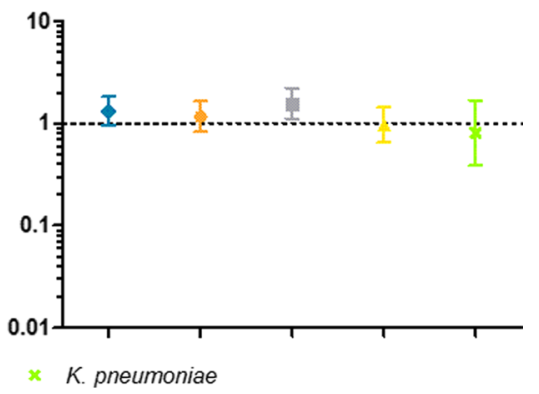

Fig. 4 Adjusted odds ratio with 95\% confidence interval for nasopharyngeal colonisation with S. pneumoniae, H. influenzae, M. catarrhalis, S. aureus and K. pneumoniae in a HIV positive versus HIV negative patients, $\mathbf{b}$ patients with versus patients without tuberculosis, $\mathbf{c}$ patients with versus patients without malaria. Figures show the correlation between determinants [HIV positivity (a), tuberculosis (b), and malaria (c)] and outcome variables (S. pneumoniae, H. influenzae, M. catarrhalis, S. aureus and K. pneumoniae carriage), after adjustment for age, sex and month of inclusion, calculated using separate logistic regression models 
a.

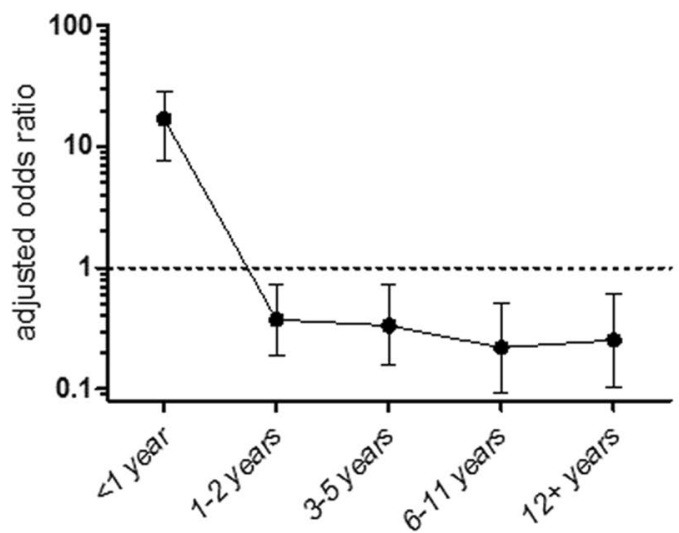

b.

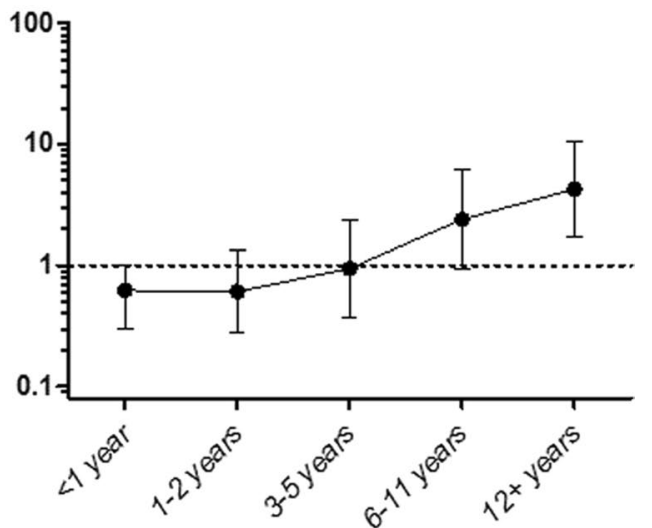

Fig. 5 Effect of colonisation with a M. catarrhalis on colonisation with S. pneumoniae, b S. pneumoniae on colonisation with S. aureus. a Shows the correlation between the determinant (colonisation with M. catarrhalis) and outcome variable (colonisation with S. pneumoniae), after adjustment for age, sex and month of inclusion, calculated using a logistic regression model. b Shows the correlation between the determinant (colonisation with S. pneumoniae) and outcome variable (colonisation with S. aureus), after adjustment for age, sex and month of inclusion, calculated using a logistic regression model

and S. aureus may be a risk factor for disease, supporting the clinical relevance of these epidemiological findings. $S$. aureus carriage was correlated with patient death independent of $S$. aureus bacteraemia. Additionally, carriage of some bacteria appeared to influence the carriage of others.

A major strength of this study is the high number of patients enrolled throughout the year, which allowed us to detect seasonal patterns and to correct for season in other analyses. Interestingly, colonisation rates were lowest towards the end of the rainy season. This may be due to ecological or climatic effects or, more likely, it could be an effect of anthropological or biological differences between seasons such as the effect of dust and dry air on the nasopharynx, crowding or seasonal effects on immune status [28]. Malaria did not appear to have a significant impact. Due to the setup of this study, which was originally designed to test and optimise an algorithm to distinguish malaria from bacterial infections in febrile patients, we were able to perform statistical analyses for a broad range of clinical parameters. The use of qPCR rather than culture allowed for detection of low grades of colonisation.

The most important weakness of this study is the inclusion of patients with a clinical suspicion of infection only. Because a significant proportion of the study population (16.8\%) was diagnosed with pneumonia and all included pathogens are capable of causing pneumonia, the carriage prevalence in the general population is probably somewhat lower than the prevalence we presented in Figs. 1 and 2, especially for S. pneumoniae. A second limitation is the change in inclusion criteria: halfway through the study, non-hospitalised patients were also eligible for inclusion, meaning that on average, the study population would be less severely ill. Thirdly, it may be possible that fever itself has an effect on the nasopharyngeal microbiome. A final factor that may have influenced the results was the use of nasopharyngeal swabs only, as the combination of nasopharyngeal and oropharyngeal swabbing has been shown to yield higher carriage rates $[19,29]$.

Despite the inclusion of patients with a clinical suspicion of fever only, the nasopharyngeal carriage prevalences we found was comparable to other PCR-based studies in West Africa. Baggett et al. [15] reported a pneumococcal carriage prevalence of $88.6 \%$ in combined nasopharyngeal and oropharyngeal swabs taken from control subjects aged 1 month to 5 years in the Gambia, and $79.1 \%$ in Mali. Park et al. [20] reported carriage rates of $51.5 \%$ for $H$. influenzae, $74.3 \%$ for $M$. catarrhalis and $24.5 \%$ for $S$. aureus in children up to 5 years of age from 7 low- and middle-income countries, including the Gambia and Mali. Kwambana et al. [30] collected nasopharyngeal swabs from Gambian children repeatedly during the first year of life: $78 \%$ of swabs tested positive for S. pneumoniae. They also tested for the presence of $H$. influenzae (70\%), M. catarrhalis (71\%) and S. aureus $(20 \%)$. It is impossible to directly compare these unadjusted prevalence data to ours, as prevalence is highly dependent on the parameters we adjusted for (age, sex and season). However, all reported prevalence falls within the range of the seasonal variation we found for the included age groups, with the exception of the pneumococcal carriage rate of $88.6 \%$ Baggett et al. reported for the Gambia, which was higher than the upper limit of the seasonal 
variation within children aged $<5$ years in our study (52.9-86.0\%).

We included $K$. pneumoniae in our study because it is known to be an important cause of CAP in low and middle income countries, comparable to $S$. pneumoniae in terms of frequency [5-7]. Carriage rates for K. pneumoniae were quite low in our population, however, especially when compared to S. pneumoniae. We also did not find the previously described pattern of higher prevalence of K. pneumoniae carriage among adults [5].

We found higher odds for pneumonia in carriers of $S$. pneumoniae (OR 1.75) and H. influenzae (OR 1.90). This correlation has previously been described for $S$. pneumoniae, $H$. influenzae and $M$. catarrhalis in other populations $[15,31]$ and may suggest that nasopharyngeal carriage of these respiratory pathogens is a first step towards invasive disease. Conversely, we did not find higher odds for pneumonia in $M$. catarrhalis carriers. Possible explanations for this contradictory finding are a lower pathogenicity of locally circulating $M$. catarrhalis or lower susceptibility to $M$. catarrhalis pneumonia in our population. As no sputum samples had been collected, we could not calculate odds ratios for nasopharyngeal colonisation with the pneumonia causing pathogen.

Nasopharyngeal carriage of $S$. aureus was associated with bacteraemia with non-S. aureus bacteria and, independent of this association, with 3.5 times higher odds for fatal illness. This could indicate that $S$. aureus carriers are at risk for more severe disease, potentially due to an immune-mediated mechanism. An alternative explanation would be that the immune response associated with severe, acute and potentially fatal infectious disease predisposes towards $S$. aureus colonisation. To our knowledge, this association has not been described before.

\section{Conclusions}

Our study provides important insights into the dynamics of nasopharyngeal colonisation with bacterial pathogens during the rainy and dry season in rural Burkina Faso, the influence of age and sex and the association between carriage of different pathogens. The presented results may help understand the spread of these pathogens and could help to determine the cause of infection in febrile patients in these regions.

\footnotetext{
Abbreviations

CAP: Community acquired pneumonia; CMA: Centre Medical avec Antenne Chirurgicale; H. influenzae: Haemophilus influenzae; HIV: Human immunodeficiency virus; IRSS: Institut de Recherche en Sciences de la Santé/Clinical Research Unit of Nanoro; K. pneumoniae: Klebsiella pneumoniae; M. catarrhalis: Moraxella catarrhalis; PaluBac: Optimizing Sysmex technology as an innovative tool to differentiate between malaria (PALUdism) and BACterial infections in a malaria endemic region; qPCR: Quantitative polymerase chain reaction; $S$. aureus: Staphylococcus aureus; S. pneumoniae: Streptococcus pneumoniae.
}

\section{Supplementary Information}

The online version contains supplementary material available at https://doi. org/10.1186/s12879-021-06996-7.

Additional file 1: Additional tables.

Additional file 2: Overview of qPCR results.

Additional file 3: SPSS output file.

\section{Acknowledgements}

The authors would like to thank all the study participants, the nurses from CMA and the study team from CRUN: Lompo Palpougouni, Salou Diallo, Bognini D. Joel, Basile Kam, Clement Zongo, Abassiri Bakombania, Catherine Nikiema, Celine Nare and Esther Kapioko for their dedication to the study. Special thanks go to Jordache Ramjith for helping with the statistical analyses.

\section{Authors' contributions}

BK, AP, HT, JJ and QM supervised the field study. LM, BK, AP, JL, AJV, QM and MIJ conceived and designed the analysis, LM and CEG conducted the experiments, LM, CEG, and MIJ performed the data analysis, LM and MIJ wrote the paper. All authors contributed to review and editing of the paper. All authors read and approved the final manuscript.

\section{Funding}

A.J.V. and Q.M. have a non-restricted research grant from SYSMEX, which funded part of the current study.

\section{Availability of data and materials}

The Additional file 1: Tables as well as the dataset containing the results of the PCRs performed on all samples, positive and negative controls and the SPSS output file are publicly available via https://osf.io/5c69q/.

\section{Declarations}

\section{Ethics approval and consent to participate}

The study was performed in accordance with the Declaration of Helsinki. The study protocol was approved by the national ethics committee of Burkina Faso (No. 2015-01-006), the institutional review board of IRSS (No. A03-2016/ CEIRES), the ethical committee of the University of Antwerp (No. 15/47/492) and the internal review board of the Institute of Tropical Medicine Antwerp, Belgium (No. 1029/15). Written informed consent was obtained from all participants or their parents/legal guardians with additional assent from those aged 7 to 15 years. The trial was registered at ClinicalTrials.gov (NCT02669823).

Consent for publication

Not applicable.

\section{Competing interests}

The authors declare that they have no competing interests.

\section{Author details}

${ }^{1}$ Department of Laboratory Medicine, Laboratory of Medical Immunology, Radboud university medical center, Nijmegen, the Netherlands. ${ }^{2}$ Department of Medical Microbiology, Radboud university medical center, Nijmegen, the Netherlands. ${ }^{3}$ Radboudumc Center for Infectious Diseases, Radboud university medical center, Nijmegen, the Netherlands. ${ }^{4}$ Department of Internal Medicine, Radboud university medical center, Nijmegen, the Netherlands. ${ }^{5}$ Institut de Recherche en Sciences de la Santé/Clinical Research Unit of Nanoro, Nanoro, Burkina Faso. ${ }^{6}$ Department of Clinical Sciences, Institute of Tropical Medicine, Antwerp, Belgium. ${ }^{7}$ Department of Microbiology, Immunology and Transplantation, KU Leuven, Leuven, Belgium.

Received: 31 Auqust 2021 Accepted: 17 December 2021

Published online: 04 January 2022 


\section{References}

1. Weiser JN, Ferreira DM, Paton JC. Streptococcus pneumoniae: transmission, colonization and invasion. Nat Rev Microbiol. 2018;16(6):355-67. https:// doi.org/10.1038/s41579-018-0001-8.

2. Agrawal A, Murphy TF. Haemophilus influenzae infections in the H. influenzae type b conjugate vaccine era. J Clin Microbiol. 2011;49(11):3728-32. https://doi.org/10.1128/JCM.05476-11.

3. Goldstein EJC, Murphy TF, Parameswaran GI. Moraxella catarrhalis, a human respiratory tract pathogen. Clin Infect Dis. 2009:49(1):124-31. https://doi.org/10.1086/599375.

4. Sakr A, Brégeon F, Mège JL, Rolain JM, Blin O. Staphylococcus aureus nasal colonization: an update on mechanisms, epidemiology, risk factors, and subsequent infections. Front Microbiol. 2018;9:2419. https://doi.org/10. 3389/fmicb.2018.02419.

5. Martin RM, Bachman MA. Colonization, infection, and the accessory genome of Klebsiella pneumoniae. Front Cell Infect Microbiol. 2018;8:4 https://doi.org/10.3389/fcimb.2018.00004.

6. Aston SJ. Pneumonia in the developing world: characteristic features and approach to management. Respirology. 2017;22(7):1276-87. https://doi. org/10.1111/resp.13112

7. Iroezindu MO, Chima El, Isiguzo GC, Mbata GC, Onyedum CC, Onyedibe $\mathrm{Kl}$, Okoli LE. Sputum bacteriology and antibiotic sensitivity patterns of community-acquired pneumonia in hospitalized adult patients in Nigeria: a 5-year multicentre retrospective study. Scand J Infect Dis. 2014;46(12):875-87. https://doi.org/10.3109/00365548.2014.954263.

8. Adegbola RA, DeAntonio R, Hill PC, Roca A, Usuf E, Hoet B, Greenwood BM. Carriage of Streptococcus pneumoniae and other respiratory bacterial pathogens in low and lower-middle income countries: a systematic review and meta-analysis. PLoS ONE. 2014;9(8): e103293. https://doi.org/ 10.1371/journal.pone.0103293.

9. Bojang A, Jafali J, Egere UE, Hill PC, Antonio M, Jeffries D, Greenwood BM, Roca A. Seasonality of pneumococcal nasopharyngeal carriage in rural Gambia determined within the context of a cluster randomized pneumococcal vaccine trial. PLoS ONE. 2015;10(7): e0129649. https://doi.org/10. 1371/journal.pone.0129649.

10. Bottomley C, Bojang A, Smith PG, Darboe O, Antonio M, Foster-Nyarko E, Kampmann B, Greenwood B, D'Alessandro U, Roca A. The impact of childhood vaccines on bacterial carriage in the nasopharynx: a longitudinal study. Emerg Themes Epidemiol. 2015;12(1):1. https://doi.org/10.1186/ s12982-014-0022-3.

11. Kaboré L, Adebanjo T, Njanpop-Lafourcade BM, Ouangraoua $S$, Tarbangdo FT, Meda B, Velusamy S, Bicaba B, Aké F, McGee L, Yaro S, Betsem E, Gervaix A, Gessner BD, Whitney CG, Moïsi JC, Van Beneden CA. Pneumococcal carriage in Burkina Faso after 13-valent pneumococcal conjugate vaccine introduction: results from 2 cross-sectional population-based surveys. J Infect Dis. 2021;224(Supplement_3):S258-66. https://doi.org/10.1093/infdis/jiab037.

12. Wolf B, Gama A, Rey L, Fonseca W, Roord J, Fleer A, Verhoef J. Striking differences in the nasopharyngeal flora of healthy Angolan, Brazilian and Dutch children less than 5 years old. Ann Trop Paediatr. 1999:19(3):287-92.

13. Eibach D, Nagel M, Hogan B, Azuure C, Krumkamp R, Dekker D, Gajdiss M, Brunke M, Sarpong N, Owusu-Dabo E, May J. Nasal carriage of Staphylococcus aureus among children in the Ashanti Region of Ghana. PLoS ONE. 2017;12(1): e0170320. https://doi.org/10.1371/journal.pone.0170320.

14. Adetifa IMO, Adamu AL, Karani A, Waithaka M, Odeyemi KA, Okoromah CAN, Bello MM, Abubakar IS, Inem V, Scott JAG. Nasopharyngeal pneumococcal carriage in Nigeria: a two-site, population-based survey. Sci Rep. 2018;8(1):3509. https://doi.org/10.1038/s41598-018-21837-5.

15. Baggett HC, Watson NL, Deloria Knoll M, Brooks WA, Feikin DR, Hammitt LL, Howie SRC, Kotloff KL, Levine OS, Madhi SA, Murdoch DR, Scott JAG, Thea DM, Antonio M, Awori JO, Baillie VL, DeLuca AN, Driscoll AJ, Duncan J, Ebruke BE, Goswami D, Higdon MM, Karron RA, Moore DP, Morpeth SC, Mulindwa JM, Park DE, Paveenkittiporn W, Piralam B, Prosperi C, Sow SO, Tapia MD, Zaman K, Zeger SL, O'Brien KL, PERCH Study Group. Density of upper respiratory colonization with Streptococcus pneumoniae and its role in the diagnosis of pneumococcal pneumonia among children aged < 5 years in the PERCH study. Clin Infect Dis. 2017;64(suppl_3):S317-27. https://doi.org/10.1093/cid/cix100.

16. Dano ID, Ousmane S, Moumouni K, Lagare A, Issa I, Testa J. Risk factors associated with Streptococcus pneumonia carriage in children under five years old with acute respiratory infection in Niger. Pan Afr Med J. 2019;33:239. https://doi.org/10.11604/pamj.2019.33.239.15945.

17. Egyir B, Guardabassi L, Esson J, Nielsen SS, Newman MJ, Addo KK, Larsen AR. Insights into nasal carriage of Staphylococcus aureus in an urban and a rural community in Ghana. PLoS ONE. 2014;9(4): e96119. https://doi.org/ 10.1371/journal.pone.0096119.

18. Foster-Nyarko E, Kwambana B, Aderonke O, Ceesay F, Jarju S, Bojang A, McLellan J, Jafali J, Kampmann B, Ota MO, Adetifa I, Antonio M. Associations between nasopharyngeal carriage of Group B Streptococcus and other respiratory pathogens during early infancy. BMC Microbiol. 2016;16:97. https://doi.org/10.1186/s12866-016-0714-7.

19. Odutola A, Antonio M, Owolabi O, Bojang A, Foster-Nyarko E, Donkor S, Adetifa I, Taylor S, Bottomley C, Greenwood B, Ota M. Comparison of the prevalence of common bacterial pathogens in the oropharynx and nasopharynx of Gambian infants. PLoS ONE. 2013;8(9): e75558. https:// doi.org/10.1371/journal.pone.0075558.

20. Park DE, Baggett HC, Howie SRC, Shi Q, Watson NL, Brooks WA, Deloria Knoll M, Hammitt LL, Kotloff KL, Levine OS, Madhi SA, Murdoch DR, O'Brien KL, Scott JAG, Thea DM, Ahmed D, Antonio M, Baillie VL, DeLuca AN, Driscoll AJ, Fu W, Gitahi CW, Olutunde E, Higdon MM, Hossain L, Karron RA, Maiga AA, Maloney SA, Moore DP, Morpeth SC, Mwaba J, Mwenechanya M, Prosperi C, Sylla M, Thamthitiwat S, Zeger SL, Feikin DR, PERCH Study Group. Colonization density of the upper respiratory tract as a predictor of pneumonia-Haemophilus influenzae, Moraxella catarrhalis, Staphylococcus aureus, and Pneumocystis jirovecii. Clin Infect Dis. 2017;64(suppl_3):S328-36. https://doi.org/10.1093/cid/cix104.

21. Post A, Kaboré B, Reuling IJ, Bognini J, van der Heijden W, Diallo S, Lompo P, Kam B, Herssens N, Lanke K, Bousema T, Sauerwein RW, Tinto H, Jacobs J, de Mast Q, van der Ven AJ. The XN-30 hematology analyzer for rapid sensitive detection of malaria: a diagnostic accuracy study. BMC Med. 2019:17(1):103. https://doi.org/10.1186/s12916-019-1334-5.

22. Post A, Kaboré B, Bognini J, Diallo S, Lompo P, Kam B, Herssens N, van Opzeeland F, van der Gaast-de Jongh CE, Langereis JD, de Jonge MI, Rahamat-Langendoen J, Bousema T, Wertheim H, Sauerwein RW, Tinto H, Jacobs J, de Mast Q, van der Ven AJ. Infection Manager System (IMS) as a new hemocytometry-based bacteremia detection tool: a diagnostic accuracy study in a malaria-endemic area of Burkina Faso. PLoS Negl Trop Dis. 2021;15(3): e0009187. https://doi.org/10.1371/journal.pntd.0009187.

23. Kaboré B, Post A, Lompo P, Bognini JD, Diallo S, Kam BTD, RahamatLangendoen J, Wertheim HFL, van Opzeeland F, Langereis JD, de Jonge MI, Tinto H, Jacobs J, van der Ven AJ, de Mast Q. Aetiology of acute febrile illness in children in a high malaria transmission area in West Africa. Clin Microbiol Infect. 2021;27(4):590-6. https://doi.org/10.1016/j.cmi.2020.05. 029.f.

24. Derra K, Rouamba E, Kazienga A, Ouedraogo S, Tahita MC, Sorgho H, Valea I, Tinto H. Profile: Nanoro health and demographic surveillance system. Int J Epidemiol. 2012;41(5):1293-301. https://doi.org/10.1093/ije/dys159.

25. District sanitaire de Nanoro. Plan d'action de l'année 2019 du district Sanitaire de Nanoro; 2019.

26. Revised WHO classification and treatment of childhood pneumonia at health facilities. Geneva: World Health Organization; 2014. http://apps. who.int/iris/bitstream/handle/10665/137319/9789241507813_eng.pdf.

27. Ngocho JS, Minja L, van der Gaast-de Jongh CE, Rahamat-Langendoen JC, Langereis JD, Mmbaga BT, de Jonge MI. Viral-bacterial (co-)occurrence in the upper airways and the risk of childhood pneumonia in resourcelimited settings. J Infect. 2020. https://doi.org/10.1016/j.jinf.2020.06.013.

28. Ter Horst R, Jaeger M, Smeekens SP, Oosting M, Swertz MA, Li Y, Kumar $V$, Diavatopoulos DA, Jansen AFM, Lemmers H, Toenhake-Dijkstra H, van Herwaarden AE, Janssen M, van der Molen RG, Joosten I, Sweep FCGJ, Smit JW, Netea-Maier RT, Koenders MMJF, Xavier RJ, van der Meer JWM, Dinarello CA, Pavelka N, Wijmenga C, Notebaart RA, Joosten LAB, Netea MG. Host and environmental factors influencing individual human cytokine responses. Cell. 2016;167(4):1111-1124.e13. https://doi.org/10. 1016/j.cell.2016.10.018.

29. Mueller JE, Yaro S, Ouédraogo MS, Levina N, Njanpop-Lafourcade BM, Tall H, Idohou RS, Sanou O, Kroman SS, Drabo A, Nacro B, Millogo A, van der Linden M, Gessner BD. Pneumococci in the African meningitis belt: meningitis incidence and carriage prevalence in children and adults. PLOS ONE. 2012;7(12): e52464. https://doi.org/10.1371/journal.pone.0052464.

30. Kwambana BA, Barer MR, Bottomley C, Adegbola RA, Antonio M. Early acquisition and high nasopharyngeal co-colonisation by Streptococcus 
pneumoniae and three respiratory pathogens amongst Gambian newborns and infants. BMC Infect Dis. 2011;11:175. https://doi.org/10.1186/ 1471-2334-11-175.

31. Tenenbaum T, Franz A, Neuhausen N, Willems R, Brade J, SchweitzerKrantz S, Adams O, Schroten H, Henrich B. Clinical characteristics of children with lower respiratory tract infections are dependent on the carriage of specific pathogens in the nasopharynx. Eur J Clin Microbiol Infect Dis. 2012;31 (11):3173-82. https://doi.org/10.1007/s10096-012-1682-y.

\section{Publisher's Note}

Springer Nature remains neutral with regard to jurisdictional claims in published maps and institutional affiliations.

- fast, convenient online submission

- thorough peer review by experienced researchers in your field

- rapid publication on acceptance

- support for research data, including large and complex data types

- gold Open Access which fosters wider collaboration and increased citations

- maximum visibility for your research: over $100 \mathrm{M}$ website views per year

At $\mathrm{BMC}$, research is always in progress.

Learn more biomedcentral.com/submissions 